Ecler Ercole Jaqua, MD

Assistant Professor, Department of Family

Medicine, Division of Geriatric Medicine,

Loma Linda University Health,

Loma Linda, CA

\section{Robert Chi, MD}

PGY-3 Resident, Department of Family

Medicine, Loma Linda University Health, Loma Linda, CA
Wessam Labib, MD, MPH

Assistant Professor, Department of Family Medicine

Head \& Medical Director, Division of Geriatric Medicine;

Director, Family Medicine Medical Student Education;

Medical Director, Department of Physician Assistant Sciences,

Loma Linda University Health, Loma Linda, CA
Marcos Uribe, MD

Assistant Professor, Department of Family

Medicine, Loma Linda University Health,

Loma Linda, CA
Juan Najarro, MD

Assistant Professor, Department of Family

Medicine, Loma Linda University Health,

Loma Linda, CA
Mary Hanna, MD

Assistant Professor, Department of Family Medicine,

Loma Linda University Health, Loma Linda, CA

\title{
Optimize your documentation to improve Medicare reimbursement
}

\section{ABSTRACT}

There's nothing more frustrating than not getting credit for work performed. Physicians often leave large amounts of compensation on the table, because even though services were provided, insurance payers do not recognize the work due to suboptimal documentation. This problem is especially apparent in preventive medicine and wellness visits with adult and geriatric patients, and results in physician services being undervalued. This article outlines specific documentation requirements for receiving full credit for the work already provided by most primary care physicians.

\section{KEY POINTS}

Billing for outpatient evaluation and management has 5 levels, determined by 3 elements: the history, physical examination, and medical decision-making. In a new patient, all 3 elements must meet the criteria for a given level to be compensated at that level, but in an already established patient, only 2 of the 3 need to.

It is important to classify geriatric visits into 2 separate categories: the new wellness visit and the standard office visit.

Many clinics have adopted screening questions to assess patients' overall health, which patients can answer by filling out a form while waiting for their visit.

To receive compensation for a preventive service, 3 components must be documented: the amount of time spent counseling, the Current Procedural Terminology code, and the linked diagnosis.
G ERIATRIC PATIENTS ARE complex. The typical older adult is more likely to suffer from severe end-stage diseases, adverse effects of polypharmacy, and lack of social support, resulting in poorer overall outcomes. The goal for the primary care physician is to address as many of these complaints as possible in an efficient matter, while documenting and billing appropriately for procedures to ensure that taking care of the geriatric population remains a cost-effective endeavor.

This article provides clear templates and instructions to ensure all geriatric services rendered are properly billed and coded for and briefly reviews general medical billing in the outpatient setting.

\section{OVERVIEW OF GENERAL MEDICAL BILLING IN OUTPATIENTS}

The Current Procedural Terminology (CPT) codes used in outpatient billing for evaluation and management are typically divided into 5 levels for new patients (99201-99205) and established patients (99211-99215), determined by the number of topics documented in the history, physical examination, and medical decision-making.

For a new patient, all 3 sections must meet the criteria for the level in order to bill for the corresponding level (Table 1).,2 For instance, if the history and the physical examination are documented to a level 3 standard, and the medical decision-making is documented to a level 4 standard, then the overall visit will count as a level 3 , despite the medical decision-making, because the history and physical were not documented at the level 4 standard. ${ }^{1}$ (A new patient is defined as one who has nev- 


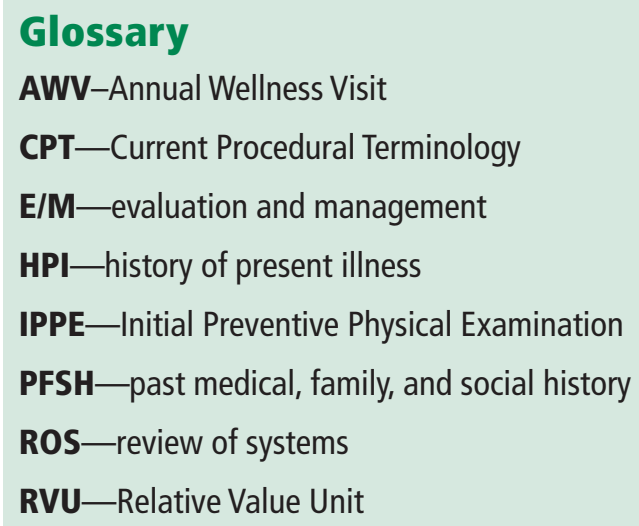

er been seen by a physician in your group, or as a patient who has not been seen in 3 years.)

In an already-established patient, only 2 of the 3 areas need to meet the documentation criteria in order to bill at a specific level ( $\mathrm{Ta}$ ble 2). For example, if the history and examination meet the criteria for level 4 , and the medical decision-making meets the criteria for level 3, the note can still be billed as a level 4 .

As a side note, billing based on time is an acceptable alternative. However, significantly more time (30 minutes) is required to bill at a level 3, which is typically completed in the 15-minute patient time slot allotted in most clinics. When billing based on time, the history, examination, and medical decision-making do not need to hit the required level of documentation. ${ }^{1,2}$

\section{for services}

that most

physicians

already provide

\section{GERIATRIC BILLING: DETERMINING THE VISIT TYPE}

It is important to classify geriatric visits into 2 separate categories: the new wellness visit and the standard office visit. This is essential because while a large portion of preventive services (depression screening, advance care planning, smoking cessation, sexually transmitted diseases screening, alcohol counseling, weight counseling, and heart disease counseling) can be administered at either category of visit, a cognitive assessment is only billable during a wellness visit or a specific visit for cognitive assessment. ${ }^{2}$ See Table 3 for the complete inclusion criteria.

However, if the patient presents for a wellness visit with a separate chief complaint, it is also allowable to "split-bill" the visit as both a wellness and standard visit as long as 2 sepa- rate notes exist for the encounter. The caveat is that a patient can only be billed for a wellness preventive visit once per year, but split billing can often dramatically increase the Relative Value Units (RVUs) generated by a single wellness visit.

\section{THE ANNUAL WELLNESS VISIT}

The annual wellness visit (AWV) is an incentive visit provided by Medicare. Many people refer to the AWV as "the yearly physical," which is a misconception. The AWV is simple, and its main focus is to perform a health risk assessment and create a personalized prevention plan.

There are 2 billable codes for an AWV: G0438-initial annual wellness visit, which can only be assigned once in a patient's life, and G0439-subsequent annual wellness visit. ${ }^{3}$ Of importance, certain documentation is required to bill for these codes (Table 4).

As a side note there is a "Welcome to Medicare" visit code (G0402) that is considered an Initial Preventive Physical Examination (IPPE) and not a billable code for AWV. The IPPE is covered only once within the first 12 months of Medicare Part B enrollment. The goal of the IPPE is essentially to review medical and social history along with health promotion, education, disease prevention, and detection. The initial AWV (G0438) can be offered 12 months after the patient received the IPPE or 12 months after the patient was enrolled under Medicare Part B. A subsequent wellness visit (G0439) can be offered annually. ${ }^{2,4}$

For more detailed information see: www. cms.gov/Outreach-and-Education/MedicareLearning-Network-MLN/MLNProducts/ Downloads/AWV_Chart_ICN905706.pdf.

This may seem like a lot of documentation, but with appropriate staff coordination, previsit data collection, and appropriate templates it will not take more than 20 minutes with documentation included. ${ }^{3,4}$ Table 5 is a sample note with the required documentation to bill for an annual wellness visit.

\section{COGNITIVE ASSESSMENT}

Cognitive assessment is an examination to evaluate a person's cognitive level, remain- 


\section{TABLE 1}

\section{New patient office visit evaluation and management codes}

Requirement (all 3 must be at the billed level)

\begin{tabular}{llllllll} 
& \multicolumn{3}{c}{ History } & \multicolumn{2}{c}{ Examination } & Medical decision-making & Time \\
Level & HPI & ROS & PFSH & Organ systems & Diagnoses/complexity/risk & (minutes) & RVUs \\
\hline Level 1 (N1) 99201 & $1-3$ & None & None & 1 & Straightforward & 10 & 0.48 \\
Level 2 (N2) 99202 & $1-3$ & 1 & None & $2-7$ (no detail) & Straightforward & 20 & 0.93 \\
Level 3 (N3) 99203 & $\geq 4$ & $2-9$ & $1-2$ & $2-7$ (with detail) & Low complexity & 30 & 1.42 \\
Level 4 (N4) 99204 & $\geq 4$ & $\geq 10$ & 3 & $\geq 8$ & Moderate complexity & 45 & 2.43 \\
Level 5 (N5) 99205 & $\geq 4$ & $\geq 10$ & 3 & $\geq 8$ & High complexity & 60 & 3.17 \\
\hline
\end{tabular}

$\mathrm{HPI}=$ history of present illness; PFSH = past medical, family, and social history; ROS = review of systems; RVU = Relative Value Unit

\section{TABLE 2}

\section{Established patient office visit evaluation and management codes}

Requirement (at least 2 of the 3 must be at the billed level)

\begin{tabular}{|c|c|c|c|c|c|c|c|}
\hline \multirow[b]{2}{*}{ Level } & \multicolumn{3}{|c|}{ History } & \multirow{2}{*}{$\begin{array}{l}\text { Examination } \\
\text { Organ systems }\end{array}$} & \multirow{2}{*}{$\begin{array}{l}\text { Medical decision-making } \\
\text { Diagnoses/complexity/risk }\end{array}$} & \multirow{2}{*}{$\begin{array}{l}\text { Time } \\
\text { (minutes) }\end{array}$} & \multirow[b]{2}{*}{ RVUs } \\
\hline & HPI & ROS & PFSH & & & & \\
\hline Level 1 (E1) 99211 & $1-3$ & None & None & 1 & Problem-focused & 5 & 0.18 \\
\hline Level 2 (E2) 99212 & $1-3$ & 1 & None & 1 & Straightforward & 10 & 0.48 \\
\hline Level 3 (E3) 99213 & $\geq 4$ & 1 & None & $2-7$ & Low complexity & 15 & 0.97 \\
\hline Level 4 (E4) 99214 & $\geq 4$ & $2-9$ & 1 & 2-7 (with detail) & Moderate complexity & 25 & 1.5 \\
\hline Level 5 (E5) 99215 & $\geq 4$ & $\geq 10$ & $2-3$ & $\geq 8$ & High complexity & 40 & 2.11 \\
\hline
\end{tabular}

$\mathrm{HPI}=$ history of present illness; ROS = review of systems; PFSH = past medical, family, and social history; RVU = Relative Value Unit

ing abilities, and capacity to function. It can be provided to any patient who exhibits any signs or symptoms of cognitive impairment, ${ }^{3}$ in either a wellness visit or a specific cognitive assessment visit (see below).

Several standardized tests are available to be used by any eligible medical provider (physicians, nurse practitioners, clinical nurse specialists, and physician assistants). Some acceptable tools to assess cognition are the Mini-Cog, Montreal Cognitive Assessment, Mini-Mental State Examination, Saint Louis University Mental Status Examination, Memory Impairment Screen, and AD8 Dementia Screening Interview. ${ }^{5,6}$

\section{Specific cognitive assessment visit}

For geriatric patients with suspected cognitive dysfunction, a specific cognitive assessment visit (CPT 99483) can be performed. The cognitive assessment visit is a stand-alone visit code and it can be cobilled with wellness visits or preventive services, but not with a standard office visit. ${ }^{5,7,8}$ It is recommended that if a cognitive assessment is performed, the entire visit should be billed as a cognitive assessment (3.44), as the total number of RVUs generated exceeds a new patient level 5 visit (3.17). The cognitive assessment visit requirements are not the same described in the AWV (Table 5). See Table 6 for the required elements that need to be documented in order to code CPT 99483.5

For more detailed information see: www. alz.org/careplanning/downloads/cms-consensus.pdf.

\section{MAXIMIZING PREVENTIVE SERVICES}

Regardless of the chief complaints, many clinics have adopted automatic screening questions or quality metrics to assess patients' 
TABLE 3

\section{Billable preventive services}

\begin{tabular}{|c|c|c|c|}
\hline Service & Wellness visit & $\begin{array}{l}\text { Standard } \\
\text { office visit }\end{array}$ & $\begin{array}{l}\text { Cognitive } \\
\text { assessment } \\
\text { visit }\end{array}$ \\
\hline $\begin{array}{l}\text { Cognitive } \\
\text { assessment }\end{array}$ & Yes & No & Yes \\
\hline $\begin{array}{l}\text { Advance care } \\
\text { planning }\end{array}$ & Yes & Yes & No \\
\hline $\begin{array}{l}\text { Depression } \\
\text { screen }\end{array}$ & $\begin{array}{l}\text { Only if patient } \\
\text { is established } \\
\text { (G0439; not } \\
\text { with G0402 or } \\
\text { G0438) }\end{array}$ & Yes & Yes \\
\hline $\begin{array}{l}\text { Smoking } \\
\text { cessation }\end{array}$ & Yes & Yes & Yes \\
\hline $\begin{array}{l}\text { Alcohol } \\
\text { screening }\end{array}$ & Yes & Yes & Yes \\
\hline $\begin{array}{l}\text { Alcohol } \\
\text { counseling }\end{array}$ & Yes & Yes & Yes \\
\hline $\begin{array}{l}\text { STD } \\
\text { counseling }\end{array}$ & Yes & Yes & Yes \\
\hline $\begin{array}{l}\text { Cardiovascular } \\
\text { counseling }\end{array}$ & Yes & Yes & Yes \\
\hline $\begin{array}{l}\text { Weight } \\
\text { counseling }\end{array}$ & Yes & Yes & Yes \\
\hline
\end{tabular}

G0439 = subsequent annual wellness visit code; G0402 = welcome to Medicare visit code; $\mathrm{G0438}$ = initial annual wellness visit code; STD = sexually transmitted disease

overall health, such as body mass index monitoring, screening for smoking and alcohol use, or even "health vital signs" such as asking patients to estimate how much exercise they perform in a week. Often, these screening questions are given to the patient on a paper form to fill out while waiting for the doctor's visit. ${ }^{6,7}$ The reason these monitoring metrics are included is to maximize the billing for any particular encounter.

To optimize potential for billable preventive services, annual wellness screening paperwork should include questions regarding depression, alcohol use, tobacco use, sexually transmitted disease risk factors, and cardiovascular risk factors. A positive answer on any of these screens should prompt a brief discussion during the encounter with the appropriate billing code and time documented. The reason for including these questions on the AWV

\section{TABLE 4}

\section{Required documentation for an initial annual wellness visit}

Demographic data

Self-assessment of health status

Psychosocial risks

Behavioral risks

Activities of daily living

Instrumental activities of daily living

Updated personal and family history

Substance use disorder assessment

List of current health care providers and suppliers

Documentation of weight, height, body mass index, and blood pressure

Detection of cognitive impairment during visit (direct observation or third-party information helps)

Depression screening

Functional ability and level of safety (ability to successfully perform activities of daily living, fall risk assessment, hearing impairment screening, home safety assessment)

Update all screenings recommended by US Preventive Services Task Force and vaccines recommended by US Centers for Disease Control and Prevention

Action plan for any identified risks

For more detailed information see: www.cms.gov/Outreachand-Education/Medicare-Learning-Network-MLN/MLNProducts/ Downloads/AWV_Chart_ICN905706.pdf

is that many counseling services can only be billed for once a year. ${ }^{7,8}$

To maximize preventive services, wellness visits should be set for at least a 30-minute time slot, not only to manage whatever chief concern the patient brings, but also to address as many positive screening questions as possible. Furthermore, having more time in the wellness visit allows for overlapping counseling such as smoking cessation, cardiac risk factor counseling, and alcohol cessation to ensure the time criterion is met for each topic. See Table 7 for the requirement time for each billable code, RVU value, and the required interval of time before each service can be billed for again. 


\section{TABLE 5}

\section{Annual wellness visit template}

\section{Reason for visit}

Chief complaint

\section{Subjective narrative}

\section{Review of systems}

"Please refer to patient-completed questionnaire (previsit template with checkboxes)."

Past medical history (diagnoses and dates)

Past surgical history

Family history

List of medications

Socioeconomic history

Substance use disorder assessment

\section{Occupational history}

Tobacco use

\section{Recent hospitalizations}

\section{Objective}

Vital signs, weight, height, body mass index

Physical examination

Vision and hearing evaluation

"Pertinent lab results and tests in the record were reviewed with the patient and a copy was provided to the patient as needed."

\section{Assessment of any cognitive impairment}

\section{General appearance}

Mood and affect

Input from others

Notes and plan

\section{DOCUMENTING FOR PREVENTIVE VISITS}

To receive compensation from Medicare for a preventive service, 3 components must be documented, ${ }^{8}$ ie, the amount of time spent counseling, the CPT code, and the linked diagnosis. This will improve Medicare reimbursement for the preventive services that a primary care physician regularly provides. However, these services are not exclusive to primary care physicians: they can be billed for by any medical specialist as long as they are properly documented
Depression screening (PRIME MD-PHQ2)

Refresh note if PHQ-9 was completed

Follow-up plan for depression

\section{Functional ability}

Does the patient exhibit a steady gait?

How long did it take the patient to get up and walk from a sitting position?

Is the patient self-reliant (can the patient do their own laundry, prepare meals, do household chores)?

Does the patient handle his or her own medications? Does the patient handle his or her own money? Is the patient's home safe (eg, good lighting, handrails on stairs and bath)?

Did you notice or did patient express any hearing difficulties?

Did you notice or did patient express any vision difficulties?

Were distance and reading eye charts used? Notes and plan

\section{Advance care planning}

Was patient offered the opportunity to discuss advance care planning?

If no, did you provide information on advance directives?

Notes and plan

\section{Smoking cessation counseling}

Electrocardiogram results Required only in initial AWV

Vaccines

\section{Screening recommendations}

Assessments and plan

and not billed by another physician (usually the primary care physician) in the specific required interval for that service. For example, if a primary care physician documents and bills for a particular service after a subspecialist does, the primary care physician won't get reimbursed.

For more detailed information see: https:// www.cms.gov/Medicare/Coding/MedHCPCSGenInfo/index.

The time documented in the services requiring time attestation cannot overlap be- 


\section{TABLE 6}

\section{Cognitive assessment visit: Required elements}

Cognition-focused evaluation including a pertinent history and examination

Medical decision-making of moderate or high complexity

Functional assessment (eg, basic and instrumental activities of daily living), including decision-making capacity

Use of standardized instruments for staging of dementia (eg, Functional Assessment Staging Test [FAST], Clinical Dementia Rating [CDR])

Medication reconciliation and review for high-risk medications

Evaluation for neuropsychiatric and behavioral symptoms, including depression, with use of standardized screening instrument(s)

Evaluation of safety (eg, home), including motor vehicle operation

Identification of caregiver(s), caregiver knowledge, caregiver needs, social supports, and the willingness of caregiver to take on caregiving tasks

Development, updating or revision, or review of an advance care plan

Creation of a written care plan, including initial plans to address any neuropsychiatric symptoms, neurocognitive symptoms, functional limitations, and referral to community resources as needed (eg, rehabilitation services, adult day programs, support groups) shared with the patient and/or caregiver with initial education and support

Typically, 50 minutes are spent face to face with the patient, family, or caregiver

For detailed information see: https://www.alz.org/careplanning/downloads/cms-consensus.pdf

tween the time for the standard office visit and the time for other preventive services. See Table 8 for examples of time attestation.

\section{REIMBURSEMENT FOR CARE PROVIDED}

The role of the primary physician is to provide comprehensive care to the individual. But often, the care provided is not reflected in the
Medicare reimbursement as a result of incomplete or inadequate documentation. While initially daunting, proper optimization of the clinic visits to include previsit screening questions, increased time slots for wellness visits, and note templates with prebuilt preventive coding can dramatically increase the RVUs generated for services that most physicians already provide. 
TABLE 7

Billing and documentation criteria for preventive services

\begin{tabular}{|c|c|c|c|c|c|c|}
\hline Service & $\begin{array}{l}\text { CPT } \\
\text { code }\end{array}$ & RVUs & $\begin{array}{l}\text { Time } \\
\text { (minutes) }\end{array}$ & $\begin{array}{l}\text { Recommended } \\
\text { diagnosis }\end{array}$ & $\begin{array}{l}\text { Required } \\
\text { interval }\end{array}$ & Other requirements \\
\hline \multirow{2}{*}{$\begin{array}{l}\text { Cognitive } \\
\text { assessment }\end{array}$} & \multirow[t]{2}{*}{99483} & \multirow[t]{2}{*}{3.44} & \multirow[t]{2}{*}{ None } & \multirow[t]{2}{*}{ None } & \multirow[t]{2}{*}{180 days } & Cognitive Assessment Template \\
\hline & & & & & & $\begin{array}{l}\text { Not the same cognitive assessment } \\
\text { described in the AWV }\end{array}$ \\
\hline \multirow{2}{*}{$\begin{array}{l}\text { Advance care } \\
\text { planning }\end{array}$} & 99497 & 1.5 & $15-45$ & \multirow[t]{2}{*}{ None } & \multirow[t]{2}{*}{ None } & \multirow{2}{*}{$\begin{array}{l}\text { Document discussion, outcomes, } \\
\text { and signed forms }\end{array}$} \\
\hline & 99498 & 1.40 & $>45$ & & & \\
\hline $\begin{array}{l}\text { Depression } \\
\text { screening }\end{array}$ & G0444 & 0.18 & $\leq 15$ & $\begin{array}{l}\text { 713.31: Encounter for } \\
\text { screening for depres- } \\
\text { sion }\end{array}$ & 365 days & \\
\hline \multirow{2}{*}{$\begin{array}{l}\text { Smoking } \\
\text { cessation }\end{array}$} & 99406 & 0.24 & $3-10$ & \multirow[t]{2}{*}{ Several ${ }^{\mathrm{a}}$} & & \\
\hline & 99407 & 0.50 & $>10$ & & & \\
\hline $\begin{array}{l}\text { Alcohol } \\
\text { screening }\end{array}$ & G0442 & 0.18 & $>15$ & Any alcohol use code & 365 days & $\begin{array}{l}\text { Patient must be having adverse } \\
\text { effects from use }\end{array}$ \\
\hline $\begin{array}{l}\text { Alcohol } \\
\text { counseling }\end{array}$ & G0443 & 0.45 & $>15$ & Any alcohol use code & $\begin{array}{l}4 \text { sessions } \\
\text { per year }\end{array}$ & $\begin{array}{l}\text { Patient must have positive alcohol } \\
\text { screen }\end{array}$ \\
\hline $\begin{array}{l}\text { STD } \\
\text { counseling }\end{array}$ & G0445 & 0.45 & $>30$ & Several ${ }^{b}$ & 180 days & $\begin{array}{l}\text { Document education and skills } \\
\text { provided }\end{array}$ \\
\hline \multirow[t]{2}{*}{$\begin{array}{l}\text { Cardio- } \\
\text { vascular } \\
\text { counseling }\end{array}$} & \multirow[t]{2}{*}{ G0446 } & \multirow[t]{2}{*}{0.45} & \multirow[t]{2}{*}{$>15$} & \multirow[t]{2}{*}{$\begin{array}{l}\text { 713.6: Screening } \\
\text { for cardiovascular } \\
\text { disease }\end{array}$} & \multirow[t]{2}{*}{365 days } & $\begin{array}{l}\text { Must include intensive behavioral } \\
\text { counseling to promote a healthy } \\
\text { diet for adults with hyperlipidemia, } \\
\text { hypertension, advancing age, and } \\
\text { other known risk factors for cardio- } \\
\text { vascular and diet-related chronic } \\
\text { diseases }\end{array}$ \\
\hline & & & & & & $\begin{array}{l}\text { If a patient has a current diagnosis } \\
\text { of hyperlipidemia and/or hyperten- } \\
\text { sion, the diagnosis codes for these } \\
\text { diseases should be used instead of } \\
\text { Z13.6; screening codes cannot be } \\
\text { used if the patient already has a } \\
\text { confirmed diagnosis }\end{array}$ \\
\hline \multirow[t]{3}{*}{$\begin{array}{l}\text { Weight } \\
\text { counseling }\end{array}$} & \multirow[t]{3}{*}{ G0447 } & \multirow[t]{3}{*}{0.45} & \multirow[t]{3}{*}{$>15$} & \multirow{3}{*}{$\begin{array}{l}\text { BMI }>30.0 \mathrm{~kg} / \mathrm{m}^{2} \\
\text { and weight-related } \\
\text { diagnosis must be } \\
\text { documented }\end{array}$} & $\begin{array}{l}\text { Month 1: } \\
\text { weekly }\end{array}$ & \multirow[t]{3}{*}{ Goal-oriented behavior } \\
\hline & & & & & $\begin{array}{l}\text { Months 2-6: } \\
\text { biweekly }\end{array}$ & \\
\hline & & & & & $\begin{array}{l}\text { Monthly } \\
\text { thereafter }\end{array}$ & \\
\hline
\end{tabular}

aFor example, F17.210: Nicotine dependence, cigarettes, uncomplicated; F17.220: Nicotine dependence, chewing tobacco, uncomplicated; Z87.891: Personal history of nicotine dependence.

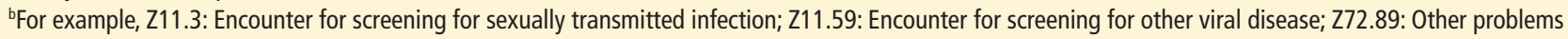
related to lifestyle; Z72.51: High-risk heterosexual behavior; Z72.52: High-risk homosexual behavior; Z72.53: High-risk bisexual behavior.

For detailed information see: https://www.cms.gov/Medicare/Coding/MedHCPCSGenInfo/index. 


\section{TABLE 8}

\section{Time attestation for $\mathbf{2}$ services}

\section{Advance care planning}

This is a time code. You must enter in the number of minutes spent on advance care planning.

Example: "I spent minutes with the patient on advance care planning."

You may also state "I have spent $>16$ minutes on advance care planning."

Template suggestion: "I spent __ minutes with the patient in counseling and discussion of goals of care, code status, and advance directives as detailed in the assessment and plan (excluding visit time and annual wellness visit time)."

\section{Depression screening}

This is a time code. You must enter in the number of minutes spent on depression screening

Example: " minutes were spent on depression screening."

You must enter in the minutes on each patient.

Template suggestion: "I spent __ minutes with the patient on screening and counseling about depression (excluding advance care planning and annual wellness visit time)."

\section{REFERENCES}

1. Centers for Medicare \& Medicaid Services. 1995 documentation guidelines for evaluation and management services. https://www.cms.gov/outreach-and-education/ medicare-learning-network-m/n/mlnedwebguide/ downloads/95docguidelines.pdf. Accessed June 4, 2020.

2. Centers for Medicare $\&$ Medicaid Services. Coding. https:// www.cms.gov/Medicare/Medicare-Fee-for-Service-Payment/ HospitalAcqCond/Coding.html. Published July 18, 2019. Accessed June 4, 2020.

3. Medicare. Yearly "Wellness" visits. https://www.medicare.gov/ coverage/yearly-wellness-visits. Accessed June 4, 2020.

4. Cuenca $A E$, Kapsner $S$. Medicare wellness visits: reassessing their value to your patients and your practice. Fam Pract Manag 2019; 26(2):25-30. pmid:30855118

5. American Academy of Family Physicians. Cognitive Evaluation. https://www.aafp.org/patient-care/public-health/ cognitive-care/cognitive-evaluation.html. Published April 17, 2017. Accessed June 4, 2020.

6. Alzheimer's Association. Alzheimer's \& Dementia. https:// www.alz.org/. Accessed June 4, 2020.

7. American Academy of Family Physicians. What is the Medicare annual wellness visit (AWV)? https://www.aafp.org/ practice-management/payment/coding/medicare-coordination-services/awv.html. Published March 20, 2017. Accessed June 4, 2020

8. American College of Physicians. How to bill Medicare's annual wellness visit (AWV). https://www.acponline.org/ practice-resources/business-resources/payment/medicarepayment-and-regulations-resources/how-to-bill-medicaresannual-wellness-visit-awv. Accessed June 4, 2020.

Address: Ecler Ercole Jaqua, MD, Department of Family Medicine, Division of Geriatric Medicine, Loma Linda University Health, 1200 California Street, Suite 240, Redlands, CA 92374; ejaqua@llu.edu 